\title{
Pelaksanaan Regulasi Penyiaran di Daerah, Studi Di Sepuluh Provinsi
}

\author{
Dian Wardiana Sjuchro ${ }^{1}$ \\ Program Studi Jurnalistik Fakultas Ilmu Komunikasi Universitas Padjadjaran
}

\begin{abstract}
Democratization of broadcasting that is characterized by the diversity of ownership and diversity of content is the aspiration that stated in Law 32/2002 on Broadcasting. However, the enormous political and business battles that follow the enactment of the broadcasting regulations have hampered its implementation in Indonesia. Now, after nearly 15 years of implementation of the Broadcasting Law in Indonesia, the time to evaluate the implementation of regulation of legislative products in the regions has arrived. Evaluations are directed more on to objective opportunities of local people to access the ownership of local television, and the impact on the content of television local to the communities. The research applies qualitative method and the data is collected by utilizing a survey to the broadcasting stakeholders in 10 areas that are determined purposively. The object of the research is local government, regional broadcasting commissions, community leaders, journalists, lecturers, and the owners of local television licensed. The results show that broadcasting regulations are relatively unworkable in the regions due to various central government policies that do not widely open the opportunities for regional people to access broadcasting licenses. This limitation also led to complaints from the region regarding the content of national television broadcasts which deemed harmful to local communities and cultures. Research respondents suggest a more pro-regional broadcasting regulation and inclusion of local people in the making of policies and regulations of regional broadcasting.
\end{abstract}

Keywords: Broadcasting, Broadcasting Regulations, Local Broadcasting,

\begin{abstract}
Abstrak
Demokratisasi penyiaran yang ditandai dengan diversity of ownership
\end{abstract}

\footnotetext{
${ }^{1}$ Korespondensi Penulis :

Dian Wardiana Sjuchro, Program Studi Jurnalistik Fakultas Ilmu Komunikasi Universitas Padjadjaran, Jalan Raya Bandung Sumedang, KM. 21, Jatinangor, Sumedang. 45363

diansjuchro@yahoo.com
} 
dan diversity of content adalah cita-cita yang tercantum dalam UU 32/2002 tentang Penyiaran. Tapi pergulatan politik dan bisnis yang intens pasca pemberlakuan regulasi penyiaran tersebut telah menghambat berbagai penerapannya di Indonesia. Sekarang, setelah hampir 15 tahun penerapan UU Penyiaran di Indonesia, tiba saatnya dilakukan evaluasi terhadap pelaksanaan regulasi produk legislatif tersebut di daerah-daerah. Evaluasi lebih diarahkan pada upaya mengetahui secara objektif peluang orang daerah untuk mengakses kepemilikan televisi lokal, dan dampak pada isi siaran televisi terhadap masyarakat di daerah. Penelitian menggunakan metode kualitatif, berupa survey terhadap stakeholder penyiaran di 10 wilayah penelitian yang ditentukan secara purposif. Objek penelitian adalah pemerintah daerah, KPID, tokoh masyarakat, wartawan, dosen, dan pemilik televisi lokal berizin. Hasil penelitian memperlihatkan bahwa regulasi penyiaran relatif tidak bisa dijalankan dengan baik di daerahdaerah karena berbagai kebijakan pemerintah pusat yang tidak membuka kesempatan lebar untuk orang daerah melakukan akses kepada perizinan penyiaran. Keterbatasan ini juga menyebabkan keluhan dari daerah mengenai isi siaran televisi nasional yang banyak merugikan masyarakat dan kebudayaan lokal. Responden penelitian menyarankan adanya regulasi penyiaran yang lebih pro daerah dan melibatkan orang-orang daerah dalam penyusunannya.

Kata kunci: Penyiaran, Penyiaran Lokal, Regulasi Penyiaran

\section{Pendahuluan}

Munculnya UU 32/2002 banyak dipandang para pengamat penyiaran sebagai upaya untuk melakukan demokratisasi penyiaran di Indonesia. Dunia penyiaran, radio dan televisi, mendapat tekanan yang luar biasa di era Orde Baru, sehingga relatif tidak mampu menjalankan perannya sebagai medium kontrol sosial. Keadaan ini menjadi lebih baik ketika UU 32/2002 meminimalisasikan peranan pemerintah (dahulu Departemen Penerangan) dalam regulasi penyiaran yang baru. Dengan peranannya yang baru, diharapkan dunia penyiaran akan lebih mampu memperbaiki posisinya sebagai medium komunikasi di tengah masyarakat.

Undang-undang No. 32/2002 tentang Penyiaran dibentuk dari serangkaian diskusi panjang mengenai peran baru dunia penyiaran di era reformasi. Tidaklah heran banyak harapan dari para pengamat media massa mengenai adanya dunia penyiaran yang lebih independen, lepas dari cengkeraman kekuasaan. Selain itu, banyak juga harapan mengenai dunia penyiaran yang lebih ramah terhadap masyarakat awan yang selama ini jauh dari kemungkinan penguasaan radio dan televisi.

Harapan-harapan tersebut kemudian menjadi semacam nyawa bagi berbagai pasal yang tercantum di dalam UU 32/2002 yang sering dipandang sebagai produk legislatif yang sangat demokratis. Di antara ketentuan tersebut adalah pasal yang menyatakan bahwa dunia penyiaran di Indonesia akan diatur melalui sebuah lembaga 
negara independen bernama Komisi Penyiaran Indonesia (KPI). Sementara pasal lainnya menyatakan bahwa perizinan untuk lembaga penyiaran (radio dan televisi) diberikan oleh negara melalui KPI.

Konsekuensi logis dari dikeluarkannya pemerintah dari urusan regulasi penyiaran adalah memberi kesempatan kepada KPI untuk menata ulang sistem penyiaran nasional yang selama ini hanya dikuasai oleh sekelompok pemodal tertentu. Sistem penyiaran nasional yang reformatif harus mampu membuka keran yang lebar bagi kepemilikan media penyiaran bagi masyarakat. Karena itu, semangat dari sistem penyiaran baru adalah adanya diversity of content dan diversity of ownership dalam dunia penyiaran di Indonesia.

Apabila ditelaah secara mendalam, Undang-Undang No. 32 Tahun 2002 tentang Penyiaran lahir dengan dua semangat utama: pertama, pengelolaan penyiaran harus bebas dari berbagai kepentingan karena penyiaran merupakan ranah publik dan digunakan sebesar-besarnya untuk kepentingan publik. Kedua, adalah semangat untuk menguatkan entitas lokal dalam semangat otonomi daerah dengan pemberlakuan sistem siaran berjaringan (Judhariksawan, 2010: 8-9).

Perjuangan KPI untuk menyusun sistem nasional penyiaran yang reformatif kemudian kandas karena banyaknya peristiwa politik pasca penetapan UU 32/2002 tentang Penyiaran. Segera setelah UU Penyiaran ditetapkan, gugatan disampaikan oleh praktisi-praktisi penyiaran ke Mahkamah Konstitusi (MK) mengenai berbagai pasal dalam regulasi tersebut. Hasilnya, MK menggugurkan kewenangan KPI untuk menjadi regulator tunggal dunia penyiaran. Bahkan MK mencabut wewenang KPI untuk membuat regulasi di bawah UU Penyiaran.

Pengamat penyiaran M.Z. Al-Faqih menggambarkan kondisi tersebut dalam sebuah pandangan yang cukup membuat miris:

Dalam PP tersebut termaktub dengan jelas bahwa izin penyelenggaraan penyiaran diberikan negara melalui menteri. Dalam pengertian menteri yang menandatangani dokumen izin penyelenggaraan penyiaran (IPP). Dalam PP tersebut KPI hanya diposisikan sebatas pemberi rekomendasi kelayakan bagi pemohon IPP. Lantas di mana filosofi penyiaran yang berada di bawah kuasa publik? (M.Z. Al-Faqih dalam Rachmiatie dan Suryadi, 2008: 62).

Pemerintah (Kementerian Komunikasi dan Informasi) kemudian mengeluarkan 7 (tujuh) paket peraturan pemerintah (PP) bidang penyiaran yang menganulir kewenangan KPI untuk menjadi lembaga independen yang mengurus segala sesuatu tentang penyiaran di Indonesia. Sesuai dengan PP Nomor 50/ 2005 tentang Penyelenggaraan Lembaga Penyiaran Swasta, KPI hanya berwewenang untuk memberikan rekomendasi perpanjangan izin serta mengawasi isi siaran. Konsekuensi logis dari dicabutnya kewenangan KPI adalah gagalnya berbagai cita-cita mengenai regulasi penyiaran yang independen.

Setelah hampir 14 tahun pelaksanaan UU Penyiaran di Indonesia, menarik untuk diketahui apakah regulasi produk legislatif ini telah dijalankan dengan baik di 
Indonesia. Hal utama yang akan menjadi perhatian utama dalam penelitian ini, yakni apakah para pelaksana regulasi telah memberi kesempatan yang cukup bagi orang daerah untuk memiliki akses bagi penguasaan lembaga penyiaran?

Untuk mengetahui hal tersebut, penelitian dilakukan dengan mendatangi stakeholder penyiaran di seluruh wilayah Indonesia, mewawancarai mereka, dengan tujuan menggali berbagai masalah di seputar hal tersebut.

\section{Metodologi}

Penelitian ini bertujuan mengevaluasi pelaksanaan UU 32/2002 tentang Penyiaran di daerah-daerah terpilih, terutama dari sisi (1) kesempatan bagi orang lokal memiliki lembaga penyiaran sendiri, serta (2) pengawasan isi siaran yang dilakukan oleh KPI terhadap radio/televisi.

Untuk mencapai tujuan tersebut, penelitian ini menggunakan metode kualitatif, sebagaimana dimaksud oleh Nelson dalam Denzin dan Lincoln (2009)

Penelitian kualitatif merupakan bidang antar-disiplin, lintas-disiplin, dan kadang-kadang kontra-disiplin. Penelitian kualitatif menyentuh humaniora, ilmu-ilmu sosial, dan ilmu-ilmu fisik. Penelitian kualitatif bermakna banyak hal pada saat yang sama. Ia memiliki fokus perhatian dengan beragam paradigma. Para praktisinya peka dengan pendekatan aneka metode. Mereka teguh dengan sudut pandang naturalistik sekaligus kukuh dengan pemahaman interpretif mengenai pengalaman manusia. Pada saat yang sama, bidang ini khas berciri politis dan dibentuk oleh beragam posisi etis dan politis.

Penelitian kualitatif merangkul dua ketegangan pada saat yang sama. Pada satu sisi, ia diseret menuju pemahaman yang kritis, feminis, post-modern, interpretif, dan luas. Namun pada sisi lain ia diarahkan menuju konsepsi tentang pengalaman manusia dan analisis post-positivis dan positivisnya didefinisikan secara sempit (Denzin dan Lincoln, 2009:5).

Penelitian dilakukan di 10 (sepuluh) provinsi di Indonesia yang ditetapkan secara purposif, berdasarkan kebutuhan penelitian. Penetapan sampel penelitian dilakukan berdasarkan kriteria wilayah NKRI (barat, tengah, timur) serta banyaknya kegiatan penyiaran yang berlangsung di wilayah tersebut.

Wilayah penelitian yang ditetapkan sebagai sampel adalah: Provinsi Jawa Barat (Bandung), Provinsi Jawa Timur (Surabaya), Provinsi Bali (Denpasar), Provinsi Kepulauan Riau (Batam), Provinsi Sumatera Utara (Medan), Provinsi Kalimantan Timur (Samarinda), Provinsi Sulawesi Selatan (Makassar), Provinsi Sulawesi Utara (Manado), Provinsi Maluku (Ambon), dan Provinsi Papua (Jayapura).

Subjek penelitian adalah stakeholder penyiaran yang ada di wilayah penelitian. Mereka adalah:

1. Pemerintah daerah, diwakili oleh Dinas Komunikasi dan Informasi Provinsi.

2. Komisi Penyiaran Indonesia Daerah (KPID)

3. Direktur lembaga penyiaran lokal yang mengantongi Izin Penyelenggaraan Penyiaran (IPP)

4. Tokoh Masyarakat, Tokoh Pendidikan setempat. 


\section{Wartawan}

6. Dosen penyiaran/Ilmu komunikasi

Data dikumpulkan melalui beberapa teknik dengan pendekatan kualitatif:

1. Wawancara Mendalam dengan para pemangku kepentingan (stakeholder) yakni KPID tiap wilayah penelitian, LSPS Televisi di daerah, tokoh masyarakat bidang komunikasi, media dan informasi dan instansi yang berkepentingan dengan regulasi penyiaran.

2. Observasi pada lembaga penyiaran dengan terjun langsung meninjau pelaksanaan atau penyelenggaran siaran di studio masing-masing.

\section{Focus Group Discussion (FGD)}

Metode penelitian yang digunakan dalam penelitian ini adalah metode kualitatif, dengan demikian, analisis data yang digunakan juga, analisis kualitatif. Pengolahan data kualitatif dilakukan dengan cara mencari tema-tema utama dari jawaban key informant untuk kemudian disusun kata kunci jawaban sebagai alat untuk menjawab pertanyaan penelitian. Selanjutnya kata kunci tersebut disusun ke dalam matriks data penelitian untuk disusun kategori atau klasifikasi jawaban untuk pertanyaan penelitian. Dari hasil tersebut dikembangkanlah paparan atau deksripsi hasil penelitian dalam bab-bab pembahasan hasil penelitian.

\section{Kajian Pustaka}

Secara teoretik, dunia penyiaran dan pers mempunyai beberapa karakteristik yang berbeda pada masing-masing negara. Mengikuti The Four Theory of The Press yang terkenal itu, dunia pers dan penyiaran terbagi paling tidak ke dalam dua kelompok besar, yakni sistem otokrasi dan sistem demokrasi. Mungkin masih ada variasi pelaksanaan sistem tersebut, tapi paling tidak dikotomi tersebut telah menggambarkan realitas yang ada.

Dunia pers/penyiaran yang otokrasi ditandai dengan dominasi pemerintah atas sistem yang berlaku. Pada negara otokrasi, negara mengeluarkan lisensi (izin) dan melakukan kontrol atas pelaksanaan izin tersebut. Penyelenggara pers dan penyiaran bisa berasal dari pemerintah atau swasta, tetapi pemerintah cenderung memberi lisensi kepada swasta yang merupakan perpanjangan tangan dari rezim yang sedang berkuasa. Dalam rangka menyelenggarakan kontrolnya, pemerintah melakukan breidel terhadap konten yang dipandang tidak sesuai dengan keinginan rezim.

Sebaliknya, dalam sistem demokrasi, perizinan bagi lembaga penyiaran diberikan oleh lembaga independen. Pengawasan isi siaran (radio dan televisi) diserahkan kepada lembaga non pemerintah yang dibentuk untuk tujuan itu (di Indonesia diserahkan ke KPI), sementara pembatalan izin hanya bisa dilakukan melalui gugatan ke pengadilan.

Perbandingan antara sistem penyiaran lama yang otokrasi dengan sistem penyiaran berdasarkan UU Penyiaran dapat dilihat dalam tabel berikut ini: 
Tabel 1.

Perbandingan Sistem Penyiaran Lama dengan Sistem Penyiaran Pasca pemberlakuan UU 32/2002 tentang Penyiaran

\begin{tabular}{|c|c|c|c|}
\hline No. & $\begin{array}{c}\text { Unsur-Unsur Sistem } \\
\text { Penyiaran }\end{array}$ & UU 24/1997 & UU 32/2002 \\
\hline 1. & Otoritas Penyiaran & $\begin{array}{l}\text { Otoritas berada di tangan } \\
\text { pemerintah, dilaksanakan } \\
\text { oleh Departemen } \\
\text { Penerangan }\end{array}$ & $\begin{array}{l}\text { Kedaulatan penyiaran } \\
\text { berada di tangan masyarakat } \\
\text { dengan mengikuti logika } \\
\text { tentang "menggunakan } \\
\text { frekuensi sebagai ranah } \\
\text { publik" }\end{array}$ \\
\hline 2. & $\begin{array}{l}\text { Perizinan, pengawasan dan } \\
\text { tindakan }\end{array}$ & $\begin{array}{l}\text { Dikeluarkan oleh } \\
\text { pemerintah (Departemen } \\
\text { Penerangan dan } \\
\text { Departemen } \\
\text { Perhubungan) }\end{array}$ & $\begin{array}{l}\text { Dilakukan oleh lembaga } \\
\text { negara independen Komisi } \\
\text { Penyiaran Indonesia (KPI) } \\
\text { yang diangkat dan } \\
\text { bertanggung jawab kepada } \\
\text { DPR }\end{array}$ \\
\hline 3. & Kepemilikan & $\begin{array}{l}\text { Pemerintah dan swasta } \\
\text { yang mendapat lisensi }\end{array}$ & $\begin{array}{l}\text { Swasta, publik dan } \\
\text { komunitas }\end{array}$ \\
\hline 4. & Sistem Birokrasi & Sentralisasi & $\begin{array}{l}\text { Desentralisasi, membuka } \\
\text { kesempatan pada daerah } \\
\text { otonom untuk turut } \\
\text { menentukan arah penyiaran } \\
\text { nasional }\end{array}$ \\
\hline 5. & Kepemilikan & $\begin{array}{l}\text { Berdasarkan pada } \\
\text { kepemilikan seorang dan } \\
\text { sekelompok orang } \\
\text { (konglomerasi) }\end{array}$ & $\begin{array}{l}\text { Diversity of ownership } \\
\text { (penyebaran kesempatan } \\
\text { kepemilikan media) }\end{array}$ \\
\hline 6. & Sifat Siaran & $\begin{array}{l}\text { Terutama televisi, sangat } \\
\text { bersifat 'Jakarta Sentris' }\end{array}$ & $\begin{array}{l}\text { Diversity of content } \\
\text { (keanekaragaman isi siaran) }\end{array}$ \\
\hline 7. & Breidel & $\begin{array}{l}\text { Pemerintah melakukan } \\
\text { kontrol melalui } \\
\text { mekanisme perizinan dan } \\
\text { pemberian lisensi }\end{array}$ & $\begin{array}{l}\text { Pencabutan izin hanya bisa } \\
\text { dilakukan melalui } \\
\text { mekanisme pengadilan } \\
\text { negeri }\end{array}$ \\
\hline
\end{tabular}

Sumber: Diolah dari berbagai sumber

Mengikuti kerangka berfikir seperti itu, maka penyiaran di Indonesia seharusnya semakin mampu menjalankan fungsinya sebagai medium yang mampu menjaga nilai-nilai demokrasi, demi terwujudnya masyarakat penyiaran yang cerdas, kritis, dan bernilai guna tinggi.

\section{Hasil Penelitian}

Penelitian ini menghasilkan gambaran deskriptif mengenai pelaksanaan UU 32/2002 tentang Penyiaran di daerah-daerah, khususnya dari segi perizinan dan kesempatan orang lokal untuk melakukan akses terhadap kepemilikan radio dan televisi swasta. Pemberian izin lembaga penyiaran televisi diberikan pemerintah dengan memperhatikan rekomendasi dari KPI Pusat (KPI)/KPI Daerah (KPID). Izin lembaga penyiaran radio dan televisi juga harus terlebih dahulu memperhatikan pengumuman pemerintah mengenai peluang usaha penyiaran, yang berbentuk Keputusan Menkominfo tentang Pemetaan Frekuensi Penyiaran Televisi/Radio pada masing-masing wilayah siaran. 
Mengantisipasi terbukanya peluang usaha di bidang penyiaran, banyak perusahaan-perusahaan swasta lokal yang mengajukan izin penyelenggaraan penyiaran (IPP) melalui KPID di masing-masing provinsi. Beberapa wilayah provinsi, misalnya Jawa Barat, Jawa Timur, dan Sulawesi Selatan, relatif kewalahan menerima pendaftar untuk izin lembaga penyiaran televisi. Tahapan yang harus dilewati oleh setiap pemohon adalah (1) mengajukan proposal pendirian lembaga penyiaran, (2) menjalani proses evaluasi dengan pendapat, dan (3) menjalani forum rapat bersama pemerintah.

Tahapan pengajuan izin tersebut, menurut para pemohon, bisa berlangsung bertahun-tahun tanpa kepastian. Hal ini banyak disebabkan karena terlalu banyaknya lembaga penyiaran yang mengajukan perizinan, sehingga terjadi antrian yang sangat panjang di KPI/KPID serta Kementerian Kominfo. Proposal menumpuk merupakan pekerjaan rumah yang memberatkan kedua lembaga untuk menyelesaikan tugastugasnya.

Selain terjadi antrian, masalah pelaksanaan perizinan lembaga penyiaran di daerah-daerah terhambat karena sangat terbatasnya kanal frekuensi yang tersedia di wilayah layanan tertentu. Seperti diungkapkan oleh para komisioner di daerahdaerah, kanal frekuensi yang seharusnya diperuntukkan untuk pemohon lembaga penyiaran lokal telah habis digunakan untuk lembaga penyiaran (televisi) yang bersiaran dari Jakarta (lazim disebut TV Nasional). Dengan kanal yang ada, sangat tipis kemungkinan televisi lokal melakukan akses terhadap perizinan televisi lokal sebagaimana diinginkan. Karena itu, banyak pemohon lokal yang terpaksa ditolak izinnya karena ketiadaan kanal frekuensi.

Masalah lain yang dihadapi KPID adalah terpusatnya permohonan izin lembaga penyiaran (radio/televisi) di wilayah perkotaan yang dipandang akan lebih menguntungkan. Hal yang kontras terjadi di daerah-daerah terpencil yang relatif kekurangan pendaftar izin radio/televisi, sehingga tidak terjadi pemerataan informasi pembangunan. Pemerataan kesempatan masyarakat di daerah terpencil tetap merupakan masalah bagi para pemangku kepentingan penyiaran di daerah-daerah, sehingga mereka memikirkan pembuatan lembaga penyiaran komunitas di daerah-daerah blank spot. Berbagai jalan ditempuh KPI/KPID untuk menyiasati kelangkaan kanal frekuensi bagi penyelenggara penyiaran radio dan televisi di wilayahnya masingmasing. Di antaranya dengan membuka kanal sekunder. Kanal sekunder adalah kanal yang tidak ditawarkan di wilayah layanan, tapi justru ditawarkan di wilayah layanan lain yang terletak dalam provinsi yang sama. Sebagai contoh, KPID Jabar yang kesulitan mendapatkan kanal televisi untuk wilayah layanan Bandung Raya, terpaksa meminjam kanal dari wilayah Cianjur yang kebetulan "mengganggur" tidak ada pemakainya. Beberapa televisi lokal Jakarta bahkan menggunakan kanal menganggur dari wilayah Malingping Banten.

Masalah penggunaan kanal sekunder ternyata tidak menyelesaikan masalah, manakala peminat terus membeludak. Beberapa KPID terpaksa mengarahkan pemohon untuk menggunakan kanal digital yang menurut rencana akan dibuka pemerintah 
pada tahun 2018 nanti. Peminat televisi digital terpaksa bersabar lebih lama manakala regulasi pemerintah tentang televisi digital tertunda-tunda akibat digugat oleh berbagai lembaga profesi karena dinilai tidak mengandung keadilan. Dalam proses gugatan tersebut pemerintah berhasil dikalahkan, sehingga perizinan televisi digital menjadi terbengkalai.

Sebuah studi yang dilakukan Agung Prabowo menyebutkan bahwa pengalaman berbagai negara yang sudah lebih dulu melakukan migrasi penyiaran analog ke digital menunjukkan bahwa banyak hal harus dipikirkan dan dikelola secara cermat. Di Inggris misalnya, persiapan untuk proses tersebut dilakukan selama 17 tahun dengan mengadakan sejumlah serial studi mendalam dan simultan tentang perilaku penonton, daya beli masyarakat, cost benefit analysis, aksesibilitas masyarakat terhadap teknologi tersebut, kesiapan teknologi, standardisasi teknologi, sampai pada serangkaian regulasi yang harus dipersiapkan untuk mengaturnya. Bahkan di Inggris, juga dipersiapkan langkah-langkah jangka panjang untuk mengelola pesawat TV analog yang tidak dipakai lagi oleh masyarakat (Prabowo, 2012).

Masalah lain yang sedang dihadapi oleh lembaga penyiaran televisi lokal adalah pengambilalihan saham perusahaan oleh konglomerat penyiaran yang notabene biasanya datang dari Jakarta. Beberapa KPID mengeluhkan mengenai banyaknya stasiun televisi lokal yang gagal bersaing sehingga diambil alih oleh stasiun televisi Jakarta. Beberapa pengamat di wilayah penelitian mengemukakan hal ini sebagai akibat gagalnya pemerintah membendung intervensi siaran televisi nasional yang lebih padat modal dan padat SDM. Persaingan televisi nasional dengan televisi lokal ibarat persaingan David vs Goliath, sehingga menyebabkan televisi lokal gulung tikar.

"Kematian" televisi lokal ternyata mengundang keprihatinan dari masyarakat di daerah yang mengeluh siaran televisi terlalu berbau Jakarta, mengabaikan nilainilai lokal (local wisdom) sebagaimana dicita-citakan UU Penyiaran. Para tokoh masyarakat dan pendidik di wilayah penelitian menilai tidak ada perubahan yang nyata dari siaran televisi Jakarta, meskipun KPI telah melakukan pengawasan terhadap isi siarannya.

Responden penelitian mengeluhkan mengenai banyaknya siaran kekerasan, mistik, infotainment, dan jurnalisme menyimpang yang dipandang akan berdampak buruk untuk masyarakat. Ancaman lain adalah hilangnya identitas lokal sebagai akibat hegemoni penyiaran yang datang dari Jakarta. Partisipan penelitian di Makassar mengambil contoh, gara-gara banyak pemberitaan tentang demonstrasi para wisatawan menjadi enggan datang ke Kota Anging Mamiri tersebut.

Mengingat kondisinya makin memburuk, para partisipan FGD di daerahdaerah mendesak akan adanya regulasi yang lebih pro daerah. Caranya adalah dengan melibatkan daerah dalam memutuskan kebijakan penyiaran di masa mendatang. Usulan mengenai regulasi penyiaran yang lebih pro kepentingan daerah tersebut mengemuka di hampir semua wilayah penelitian, sehingga sangat layak 
untuk menjadi perhatian bagi semua pemangku kepentingan.

\section{Simpulan}

Penelitian mengenai pelaksanaan regulasi di 10 provinsi di Indonesia memperlihatkan kondisi buruk peta bisnis penyiaran di daerah-daerah. Kondisi ini antara lain disebabkan tidak adanya political will dari pemerintah pusat untuk menjalankan amanat UU Penyiaran tentang adanya diversity of ownership dan diversity of content. Kesempatan orang-orang daerah untuk memiliki stasiun televisi sangat kecil, antara lain karena mereka dibiarkan bersaing secara tidak seimbang dengan stasiun televisi nasional yang sudah terlebih dahulu mempunyai sejarah panjang di bisnis pertelevisian. Di masa depan perlu dipikirkan sebuah regulasi penyiaran baru yang lebih berpihak kepada kepentingan lokal, sesuai harapan partisipan penelitian ini di daerah-daerah.

\section{Daftar Pustaka}

Denzin, Norman K \& Yvonna S. Lincoln (ed). 1998. Collecting and Interpreting Qualitative Materials. New York: Sage Publications.

Judhariksawan. 2010. Hukum Penyiaran. Jakarta: Rajawali Pers.

Prabowo, Agung. 2012. Era Penyiaran Digital: Pengembangan atau Pemberangusan TV Lokal dan TV Komunitas? Artikel Ilmiah. Jurnal Komunikasi ASPIKOM. Volume 1, No. 4, Januari 2012.

Rachmiati, Atie \& Karim Suryadi, 2008. Dinamika Penyiaran di Jawa Barat. Bandung: Komisi Penyiaran Indonesia Daerah (KPID) Jawa Barat. 